This item was submitted to Loughborough's Research Repository by the author.

Items in Figshare are protected by copyright, with all rights reserved, unless otherwise indicated.

\title{
PEArL: a systems approach to demonstrating authenticity in information systems design
}

\section{PLEASE CITE THE PUBLISHED VERSION}

http://dx.doi.org/10.1080/02683960010028438

\section{PUBLISHER}

(C) Palgrave Macmillan

\section{VERSION}

AM (Accepted Manuscript)

\section{PUBLISHER STATEMENT}

This work is made available according to the conditions of the Creative Commons Attribution-NonCommercialNoDerivatives 4.0 International (CC BY-NC-ND 4.0) licence. Full details of this licence are available at: https://creativecommons.org/licenses/by-nc-nd/4.0/

\section{LICENCE}

CC BY-NC-ND 4.0

\section{REPOSITORY RECORD}

Champion, Donna, and Frank A. Stowell. 2019. "Pearl: A Systems Approach to Demonstrating Authenticity in Information Systems Design". figshare. https://hdl.handle.net/2134/18608. 


\title{
PEArL: a systems approach to demonstrating authenticity in information systems design
}

\author{
D. CHAM PION and F. A. STOWELL \\ Department of Computer and Information Sciences, De Montfort University, Milton Keynes, UK
}

\begin{abstract}
The process of information systems (IS) design has been dominated by the demands inherent in providing a technical solution to a perceived problem or need. Engineering IS design methods applied in order to satisfy the problem situation tend to have a preoccupation with verifying specifications as being mathematically correct. Difficulties arise when the ideas underpinning verification are extended in an attempt to 'prove' the validity of a proposed design for an IS. A pure engineering approach does not facilitate a response to the subjective elements within social situations, which experience has shown to be essential in demonstrating the pertinence of new designs to those concerned. We suggest that, by applying interpretivist systems ideas, it is possible to support concerned individuals in reflecting upon crucial aspects of the inquiry, enabling those individuals to judge the relevance or 'authenticity' of the learning, according to their own values and beliefs. The elements of participants, engagement, authority, relationships and learning are suggested as being crucial. These make up the mnemonic PEArL, which is offered as an aide-mémoire for those concerned with IS design.
\end{abstract}

\section{Introduction}

There is growing acknowledgement within the field of information systems (IS) that methods of validating designs for IS and evaluating their performance need to take the subjective nature of 'information' into account (Powell, 1992; Farbey et al., 1993; Myers, 1994; Checkland and Holwell, 1998a; Smithson and Hirschheim, 1998; Stowell, 2000). However, there are few guidelines available for supporting concerned individuals in making what are essentially subjective judgements concerning the relevance of design changes within a situation of concern and, in so doing, establishing the 'validity' of a proposed intervention. Experience has shown that, in the domain of IS design, gaining acceptance of proposed change is vital to the success of any intervention into the situation (Mumford and Weir, 1979; Stowell and West, 1994; Mumford, 1996; Smith, 1997; Stowell et al., 1997; Stowell, 2000). One of the inherent difficulties in demonstrating the credibility of intervention to concerned individuals stems from the 'unrepeatability' of an inquiry in complex, dynamic social situations involving human actors. Checkland and Holwell (1998b) suggested that a notion of 'recoverability' is useful when undertaking such inquiry. However, the difficulty of how to demonstrate to concerned individuals, who may not have participated in the investigation, that the inquiry has been relevant to the situation of concern remains.
In this paper, we first argue that the success of engineering methods in designing information technology has often resulted in a preoccupation with verifying specifications for IS as being mathematically correct. Difficulties arise when the ideas underpinning verification are extended in an attempt to 'prove' the validity of a proposed design for an IS. We suggest a practical interpretivist approach to establishing the authenticity or otherwise of inquiry into IS design. If an inquiry process is acknowledged as being authentic it is more likely that concerned individuals will accept the 'validity' or relevance of any design proposals resulting from the learning. By applying systems ideas, we argue that the elements within the mnemonic PEArL (participants, engagement, authority, relationships and learning) support reflection on the inquiry process, enabling the character of an inquiry to be appreciated by anyone interested, whether or not those individuals physically participated in the inquiry (see the section on relationships towards the end of the paper for the reasoning behind the use of a lower case ' $r$ ' in PEArL). Such an appreciation supports interested and concerned individuals in making a judgement on whether they accept the results of such an inquiry as being authentic or not. The elements within PEArL are not intended to suggest criteria for or direct individuals in making those judgements. It is a tool for supporting reflection on an inquiry undertaken within group situations. 


\section{Conventional views of validation}

Most practitioners and researchers in the field of IS design would accept that there is a crucial difference between 'validation' and 'verification' of the requirements for IS. Verification of any software or technological provision entails precise testing in order to prove, often mathematically, that the product is sound and reliable (Pressman, 1997; Pooley and Stevens, 1999). Validation of the requirements for a design is regarded as a process of ensuring that the supplied technological provision meets the needs of the customer (Pressman, 1997; Sommerville and Sawyer, 1997). Pragmatically, the difference is often described as 'building the product right' (verification) and 'building the right product' (validation). Formal engineering approaches to software development apply standard procedures of measurement and control in order to ensure that uniformity and quality standards are met (Pooley and Stevens, 1999). Such approaches put primary importance on the knowledge gained through quantifiable empirical evidence. Within the complex process of ensuring a product functions correctly by checking programming algorithms, such procedures are entirely appropriate. Problems arise when the ideas underpinning verification are applied beyond their field of relevance. This has led to an undue emphasis on developing formal methods of validation based on publicly tested rules (Smithson and Hirschheim, 1998).

Formal engineering methods appear to attempt to reduce complex social situations to sets of needs or requirements (Checkland, 1981, 1983). The requirements are then compiled into a document that comprises a statement on what technological provision is to be supplied in an attempt to improve the situation. The approach is driven from the beginning by the need to order the details of the design in a format suited to the application of software engineering techniques. Sommerville and Sawyer (1997) regarded validation as being '... concerned with checking the requirements for omissions, conflicts and ambiguities and ensuring that the requirements follow quality standards' (p. 189). Sommerville and Sawyer (1997) accepted that there is no means of being absolutely certain that requirements are correct, but suggested that the requirements document can represent '. . . a clear description of the system for design and implementation' (p. 191). Graham (1998) described a validation method for a workshop situation where people pass round beanbags in order to simulate messages in the design. The focus in approaches such as these is one of demonstrating to the client that the software products will function correctly. Finlay and Wilson (1997) reviewed validation methods applied to the implementation of decision support systems, but again the focus was on demonstrating the accuracy, precision and robustness of the technological provision to 'end-users'. This impetus on proving to customers that the system to be built will be 'reliable' is different to the process of establishing that the described technological provision is relevant to the situation of concern. It seems that engineering approaches to IS design have constrained the notion of validation to only tangible elements of the technological provision that can be measured, quantified or physically demonstrated in some manner.

Lycett and Paul (1999) suggested that 'component assembly' could provide the required technical flexibility for meeting the demands of a complex and dynamically evolving business environment. Component-based architectures for software design are built on the premise that it is possible to remove, reconfigure and replace components without disturbing other parts of the system (Nierstrasz and Meijler, 1995; D'Souza and Wills, 1998). Such approaches are accepted as being an extension of the principles of modularity and reuse (Lycett and Paul, 1999). Difficulties arise with this sort of approach when attempting to implement change within a social situation. Complex business and organizational problems are segmented into separate elements so that the engineers can achieve technological resolution. The belief is that discrete elements of the problem can be tackled separately and then be reconnected in different ways in order to produce a predictable outcome. Checkland (1983) eloquently argued that such approaches lose the holistic sense of a situation and, with this reduction, meaning and relevance are also lost. Although Lycett and Paul (1999) accepted that there could be no single optimal system, by applying these techniques there seems to be an attempt to provide short-term 'solutions' by supplying faster and 'better' technology.

There can often be considerable pressure to provide a working 'solution' as quickly as possible (Pooley and Stevens, 1999). Prototyping is now widely used as a means of designing the technological provision within a situation. New technology today is often provided in incremental stages. Initially, a basic prototype is implemented and the functionality is gradually developed in following releases. Pooley and Stevens (1999) suggested building throwaway prototypes '... for the purpose of checking there is a common understanding about requirements' (p. 228). However, such methods are still entirely fixated on supplying the technological provision and, thus, are limited in their application. Prototyping may help those who are unfamiliar with technology or who wish to experiment with different interfaces. However, an IS encompasses far more than the physical hardware and software that make up the 
technological provision. Engineering methods to date have contributed to remarkable advances in the manner in which people work within their situation of concern. However, an examination of the relevance of an IS in supporting desired action within a complex human social situation demands a wider perspective. The perceived relevance and acceptability of an intervention is crucial to the success of any proposed change. The alternative to a technology-driven approach is to attempt to understand the problems and issues facing people within their situations. Change to the IS can then begin to be perceived as an attempt at bringing improvement to people undertaking purposeful action within a situation.

\section{Approaches to validation within collaborative design}

Collaborative approaches to IS design such as ETHICS (Mumford and Weir, 1979; Mumford, 1996, 1997), client-led design (Stowell, 1991, 2000; Stowell and West, 1994), multiview (Avison and WoodHarper, 1990) and participative design (Kensing and Munk-Madesen, 1993; Beyer and Holtzblatt, 1997; Kensing and Blomberg, 1998) attempt to address the complex issues to be found within human social environments. A commonality amongst all of these approaches is the reliance on physical participation in the inquiry process in order to create an acceptance for and validation of the proposed change. Tsoukas (1993) suggested that anti-positivist approaches to demonstrating the validity of knowledge, which depend on the extent to which individuals participate in the learning process, can lack rigour as public discussions can easily give way to ' . . private, intuitive, trial and error occurring in a single-mind' (p. 328). Interpretivist approaches to inquiry such as action research have often been criticized as lacking the 'rigour' of scientific methods of inquiry and at times as having a tendency towards being merely anecdotal narratives of events (Susman and Evered, 1978; Checkland and Scholes, 1990; Somekh, 1995; Walsham, 1995; Baskerville and Wood-Harper, 1996).

From an interpretivist perspective, this problem of validating an inquiry process, which cannot by its very nature be repeated to those outside the inquiry process, is a huge challenge. Checkland and Holwell (1998b) argued that, when undertaking interpretivist inquiry approaches such as action research, a concept of 'recoverability' is essential as this will support interested individuals in undertaking a scrutiny of the results. Dash (1999) suggested that there is a need for more than a concept of 'recoverability' if the aftereffects of an inquiry are to be examined and if a full account of the nature of the inquiry is to be provided. We concur with this view and suggest that, if an inquiry process can be established as having been undertaken in an authentic manner, the pertinence of the results is more likely to be accepted as a valid contribution to the situation of concern. In a real world situation, it is often necessary to foster acceptance of the authenticity of an inquiry amongst a wider group of people than those physically involved in the learning process. For example, it is not always possible or feasible to include all of those who may be implicated by changes to an IS in an inquiry into its development. The cost of allowing staff to be involved in collaboration may be prohibitive and so a small group may be delegated the task. In addition, in the current business environment, high staff turnover or simply the dynamics of business operations may mean that the personnel responsible for implementing the change are not the same as those who were involved in the design process. The soft systems methodology (SSM) developed by Checkland $(1981,1983)$ and others (Smyth and Checkland, 1976; Wilson, 1984; Checkland and Scholes, 1990, 1999) is a methodology that was designed with the purpose of guiding a practitioner in the attempt of making sense of complex human social situations. The fundamental aim of those applying SSM is to regard the views of those involved as being prime and to create a shared understanding of the situation of concern. This is difficult as the diversity of views to be found within any social setting will lead to complex, unstructured problem situations. Checkland (1981) argued that searching for an efficient solution in such situations was inappropriate as a single desired end could not be defined. However, he suggested that, by applying systems thinking, it was possible to attempt to make sense of situations. The concept of 'systemicity' is moved from the real world and instead applied to 'structuring a debate' (Checkland, 1981). 'Systems thinking' is used as an epistemology for understanding human activity.

\section{A systemic process of inquiry}

Technology-driven IS design approaches regard human activity and decision making as being goal oriented (Checkland, 1981, 1983; Stowell, 1991, 2000; Stowell and West, 1994). There is an emphasis on identifying explicit, desired objectives with the route to these ends being clearly defined. Such a causal, deterministic view of the world limits the sense of a situation by ignoring elements of uncertainty, subjectivity and ambiguity. Vickers (1965) argued for a notion of relationshipmaintaining systems as a means of modelling 'organization'. He suggested that seeking goals is an unusual, 
special case within the activity of 'maintaining through time a complex pattern of relationships in accordance with standards, or within limits that have somehow come to be set as governing relations' (Vickers, 1965, p. 41). Human intervention in a situation is always an attempt at regulating the relationship to a more acceptable level to those associated with it (Vickers, 1970). In goal-oriented approaches to design, there is a tendency to identify a specific problem and treat it as if it were the only difficulty (Vickers, 1965). However, those involved in implementing an IS need to consider the whole situation and the relationships implicated in any proposed change. Intervention and change need to be designed from a position of understanding of the problems faced by those involved. Such a philosophical stance is considered to be within the phenomenological, interpretivist school of thought (Burrell and Morgan, 1979). In placing the concerns of those immersed in the situation as prime, we are attempting to reverse the current focus of design approaches.

Many authors have argued that linking SSM to a method for deriving a technical definition for a computer-based IS would help overcome some of the disadvantages of technique-focused IS design (Stowell, 1985, 2000; Sawyer, 1992; Lewis, 1993; Stowell and West, 1994; Mingers, 1995; Savage and Mingers, 1996; Liang et al., 1998). However, there are difficulties. During the process of undertaking SSM, models describing systems that are perceived to be relevant to the situation of concern are constructed and employed as debating tools with those involved. The debate helps to increase the shared understanding of problems within the area of concern. The models also support reflection and debate about possible interventions with a view to bringing improvement, but are not themselves descriptions of possible real world activity. However, the modelling methods used to describe technical specifications were developed with the express purpose of defining the elements within the system to be built. These models emphasize the organization of the data and messages that must be passed in order for the real world technological provision to function correctly. In the process of changing the emphasis from thinking about the action to be undertaken within the situation to a focus on creating a technical definition it is difficult to maintain a direct link between the two modelling approaches (Doyle and Wood, 1991; Stowell and West, 1994; Savage and Mingers, 1996). In order to enable clients to take ownership of the proposed change, there is a need for new modelling methods for supporting their complete participation (Stowell, 2000).

\section{Interpretivist discovery of requirements}

The UMISD (1998) project A Unified Mechanism for Information Systems Definition was undertaken with the aim of developing practical interpretivist approaches to IS design. This project was part of the programme Systems Engineering for Business Process Change (SEBPC, 1996), which is funded by the Engineering and Physical Sciences Research Council. The theoretical underpinnings and modelling methods under development have been discussed fully elsewhere (Liang et al., 1998; Champion and Stowell, 1999a,b; Guo et al., 1999; Korn, 1999; Stowell, 2000). In order to guide the research, a model has been developed which expresses our understanding of how to operationalize a systemic process of interpretivist IS design and which is capable of establishing authenticity amongst concerned individuals. This is represented in Figure 1.

The models created as part of our described approach to IS development can act as a record of the learning undertaken. However, there may be a need for other concerned individuals, who did not participate in the investigation, to make judgements concerning the authenticity of the inquiry and the relevance of any suggested intervention. An examination of the models alone would not provide insight into the manner in which the inquiry was undertaken. There will be other outcomes from the learning that will be pertinent to the relevance of any proposed intervention. We suggest that, by employing systems ideas, it is possible to support a reflection on the authenticity of an inquiry into IS design.

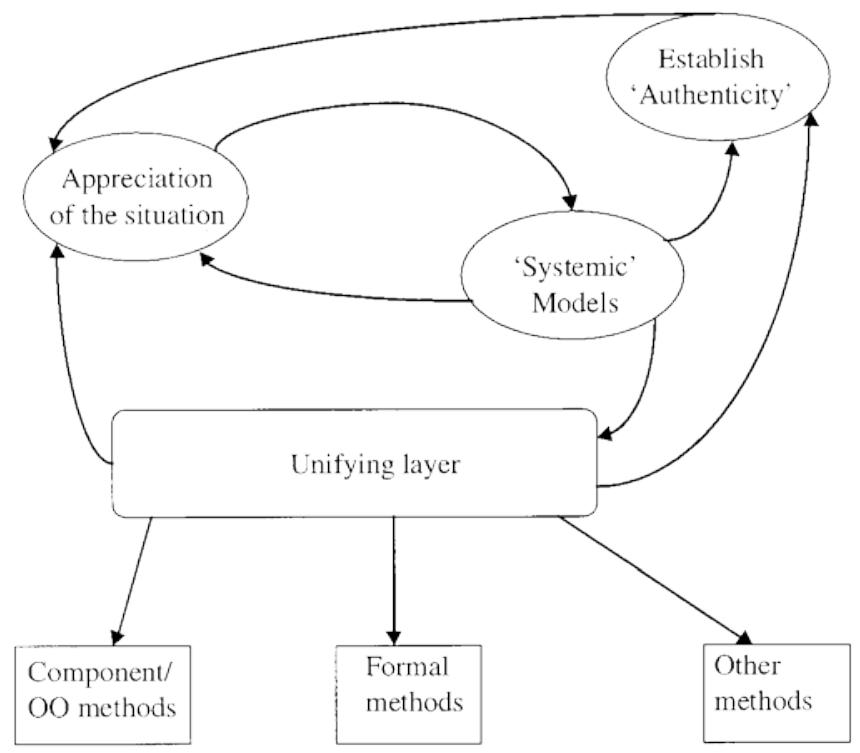

Figure 1 A model for interpretivist, systemic inquiry for IS design. Developed from a model in Stowell and Champion (2000) 


\section{Developing a concept of authenticity}

'Authenticity' as a concept is often thought of as belonging within the school of philosophy known as 'existentialism'. Heidegger (1962) and Sartre (1966) both discussed authenticity as being the exercising of freedom to choose one's own character or destiny. Burrell and Morgan (1979) suggested that the fundamental difference between existentialism and phenomenological philosophy is the '... political commitment [of existentialist approaches] to the desirability of change in the existing social order' (p. 302). This impetus for understanding the world and changing it, which is also found in the work of Foucault (1980) and Habermas (1990), is characteristic of socalled 'critical' approaches to inquiry. Practitioners subscribing to critical approaches argue the need for methods of inquiry for addressing the issues of power and coercion existing within social contexts involving human actors. Total systems intervention (TSI) (Flood and Jackson, 1991) and critical systems heuristics (CSH) (Ulrich, 1983, 1991) are often cited as being approaches which support practitioners in bringing about change to the power structures in a situation through debate (Clarke and Lehaney, 1999). The insistence of practitioners adopting critical approaches to inquiry that participants require emancipation from some condition of being 'coerced' (Boudreau, 1997) seems to be based upon the assumption that the practitioner is somehow already 'emancipated' and is therefore in a position to free others from constraint. For example, Midgley (1997) argued for 'direct political action and campaigning' to '... create the conditions, under which debate and therefore change becomes possible' (emphasis in original). However, such an approach provides space for the 'politically active' to retain their influence within a situation whilst not necessarily providing support to the less confident. Indeed, Midgley (1997) accepted that political action is only likely to be undertaken by those with sufficient self-confidence and education to articulate their opinions in an open forum.

We subscribe to a phenomenological, interpretivist, philosophical approach of 'non-interference' as we believe it is for all those involved in the situation of concern to make a judgement for themselves concerning what is acceptable, according to their own values and beliefs. As we can never be certain we understand every nuance within a situation, in a practical sense we prefer to take purposeful action in the uncertain and ambiguous situations to be found in human society, assuming a degree of tolerance and respect amongst those involved. The intention is to reach an accommodation (not necessarily consensus) concerning what is considered to be 'acceptable'. We argue that, by supporting all concerned individuals in undertaking reflection on the character of an inquiry process, then each person can decide for themselves whether to accept the validity of any resulting proposals for change. We suggest there is seemingly a dearth of such guidelines for use in practical situations in both phenomenological and critical approaches to inquiry.

Checkland (1983) argued that demonstrating the authenticity of qualitative knowledge would always be problematic as the different actors all take as given ‘... very different descriptions of the world, or Weltanschauungen' (p. 671). He suggested that engaging participants in a systemic learning process and making records of the knowledge created could enable those involved to recognize the authenticity of that knowledge (Checkland, 1983). The difficulty in establishing the credibility of a process of inquiry into areas of concern that are intangible, subjective and elusive recurs throughout research and investigation into social issues. We suggest that, when undertaking an inquiry of this nature, a concept of authenticity is helpful to those involved in the inquiry process. The work of Sartre (1966) imbued authenticity with a meaning of individual free choice. In addition, the word authentic is defined in the Oxford English Dictionary as 'possessing original, or inherent authority; [ . . . ] entitled to acceptance, or belief; of established credit' (Sykes, 1996). It is this concept of 'established credibility' and of 'acceptance' that we suggest is vital if the learning outcomes from an inquiry are to be accepted as relevant or 'valid' to the situation in focus. Participation is one means of achieving ownership of the results from a learning process but, as already described, this may not always be practical or possible. We consider that establishing the authenticity of an inquiry process involves

an exposition to those involved in and implicated by an inquiry that the manner in which a collaborative learning process was undertaken is acceptable to those concerned and the results are pertinent to the situation of focus.

By 'implicated' and 'concerned' we mean those who are affected by or concerned with the results of the inquiry, regardless of whether or not they were involved in the learning process. Checkland and Scholes (1990) suggested that subjective, qualitative interventions would be perceived as being useful and successful through practical outcomes in the domain of interest. However, there may be difficulties persuading people within the situation to even attempt the proposed change, particularly if they were not involved in the learning process. We argue that, to establish the authenticity of an inquiry, both amongst participants and others eventually implicated in change, it is 
important to consider which elements of an inquiry process will contribute to a sense of authenticity at the start of the inquiry. However, learning cannot be predicted at the start and so establishing authenticity is problematic. We suggest that it may be possible to make evident the authenticity of knowledge created through a systemic learning process by reflecting upon and, if necessary, making a record of certain crucial elements of the inquiry as it unfolds.

\section{Essential criteria required to establish authenticity}

Susman and Evered (1978) considered the difficulties inherent in attempting an action research learning cycle. They argued that, by planning and recording the inquiry process and by specifying the learning created, the inquiry would be shown to have been conducted with rigour. We suggest that, by extending the ideas of Susman and Evered (1978) and lessons learnt from the work undertaken at Lancaster (Checkland, 1981; Checkland and Scholes, 1990, 1999; Checkland and Holwell, 1998a), it may be possible to facilitate the recognition of the authenticity of an inquiry by participants and other concerned individuals. In particular, the concept of the CATWOE (customer, actor, transformation, Weltanschauung, owners and environment) test for root definitions (Smyth and Checkland, 1976) seems useful. Smyth and Checkland (1976) suggested the six elements of CATWOE as being essential to consider when defining a purposeful system. These elements provide an aide-mémoire for an SSM practitioner when constructing root definitions in order to ensure that all the crucial aspects of a particular system have been considered. Smyth and Checkland (1976) suggested that, if one of these elements is omitted, then this should be as a result of a conscious decision. However, the CATWOE mnemonic does not transfer to the outset of an inquiry when knowledge has yet to be created. For example, it is not possible to guess at the start what transformation may occur as a result of the learning. Although it may at times be possible to make an intelligent guess concerning the potential customers and actors within some situations, we could never be certain that we had considered all those who might be implicated by intervention. However, the idea that we can regard the inquiry process as being a system in itself (Checkland, 1981) would suggest it ought to be possible to create a set of essential elements that support those concerned in developing an appreciation of a holistic view of the character of an inquiry. Such a method could never be a 'test' in the same manner as applying the CATWOE elements to a root definition. An inquiry process is complex and dynamic and a method for supporting reflection of such a process needs to be similarly flexible. Creating a sense of the character of the inquiry process, possibly in the form of some record, could support those concerned in appreciating how that inquiry process was conducted, the manner in which the learning unfolded and the reasons underpinning the decisions that were made. Concerned individuals could then reflect and make judgements about whether they perceive the inquiry and outcomes to be authentic and acceptable, according to their own values.

\section{The elements of PEArL}

We suggest that the mnemonic PEArL can provide guidance as to which elements of an inquiry process are essential to reflect upon and record as the learning unfolds. PEArL is based on the ideas underpinning CATWOE and is an attempt to guide the IS practitioner in creating a sense of the 'character' of the inquiry. It is not our intention to suggest the construction of an absolute account of the inquiry process, but to create a history that is able to support reflection and enable those concerned or interested to 'recover' the manner in which the inquiry unfolded and appreciate what transpired during the learning process.

The PEArL elements support reflection in a manner suited to systemic inquiry. Any explicit mandate on the exact elements to record would be too inflexible to be useful within the complex situations that exist within any human social grouping. In addition, methods employed in undertaking social inquiry ought not to attempt to lead the results towards a particular outcome (Susman and Evered, 1978; Checkland, 1981; Champion and Stowell, 1999c). However, while not directing learning towards some 'known to be desired end', it is equally important to avoid purposeless wandering and wasted effort. It is in this spirit that the following elements are offered as an aidemémoire for guiding the IS practitioner when entering into a situation and supporting reflection on an inquiry process within group situations. The underpinning idea is that those involved in the learning are open to discovery and creativity and, in addition, that the reasons for any proposals resulting from the inquiry will need to be demonstrated as being useful and authentic to others.

\section{Participants in the inquiry}

Participatory design approaches (Kensing and Blomberg, 1998), ETHICS (Mumford, 1996) and client-led design (Stowell and West, 1994) all argue the importance of ensuring that the main stakeholders are 
included in the design and development process. However, the outcome cannot be known at the beginning of an inquiry into IS design and so it is not always possible or feasible to include all those who may be implicated by any proposed action. As iterations of the learning cycle are undertaken, proposals for intervention may implicate people who are unable to take part or who, for some reason, are not included. Reasons for non-involvement are as important as the reasons for participation when considering the authenticity of an inquiry. For example, involving a wide range and number of participants often increases the cost and complexity of any investigation into a situation, so participation may be restricted. The choice of participants, criteria for inclusion and reasons for non-involvement are all matters that need to be reflected upon. This sets a boundary, which may alter as the inquiry proceeds. It is perhaps worth reiterating at this point that PEArL is not intended to direct or suggest criteria for the decisions made by those involved in the inquiry process. This is entirely a matter for those involved in the inquiry process. PEArL is intended to support reflection on the judgements that are made during an inquiry.

\section{Engagement in the learning process}

The methods and tools employed in engaging people in the learning process reflect not only the environment in which the learning took place but may also encourage some people to participate more than others. Others may be almost entirely excluded, particularly if methods requiring specific technical expertise are employed. For example, in an attempt to link SSM to Jackson's (1983) systems development, Savage and Mingers (1996) argued that the complexity of the notation might exclude some clients from participating in that phase of the design process. The manner in which people were engaged in the learning process is then a matter to reflect upon as fully as possible. The 'engagement' of participants in the inquiry will also be reflected by any limits set on the time permitted for investigation and resources allocated. Restrictions may only become apparent when the inquiry is under way or if they alter during the course of the investigation. Recording any constraints operating during the learning process will enable those concerned to reflect upon the limitations placed on participants engaging in the learning process.

\section{Authority}

Any process of inquiry within an organizational setting will normally be sanctioned by the person or group concerned with the situation under investigation. This individual or group of people may or may not be further involved with the actual inquiry process. The participants may be supported through the time allowed for investigation, intellectual support, emotional or physical support or financial support. The authority for different aspects of the inquiry may thus be given by different people or groups and will influence the degree of 'self-governance' of those participating in the inquiry. Recording who authorized or supported which elements of the inquiry and for what purpose is essential if concerned individuals are to make a judgement concerning the authenticity of the inquiry, according to their particular beliefs and values.

\section{Relationships}

An examination of the planned relationships within any proposed change may be useful in questioning any undeclared assumptions and world views (or Weltanschauungen) held by participants. We perceive this particular element as being of fundamental importance when reflecting on the character of the inquiry. Within the PEArL mnemonic we have designated the ' $r$ ' for relationships as being lower case, the intention being to reflect a 'soft' interpretivist approach to the issue of power within a situation. Change to an IS will almost always imply some change to the relationships to be maintained within the situation in focus. The relationships reflected in the proposed intervention may provide some insight into how the issues of individual power and control have been dealt with by participants during the inquiry. Stowell (1989) suggested regarding power as a commodity and Checkland and Scholes (1990) took up this suggestion in SSM, mode 2. Applying the 'power as a commodity' metaphor facilitates asking how power has been expressed within the situation and how people intend to use and maintain these 'commodities'. Reflecting on the proposed relationships within the situation in focus will facilitate the recognition of potential beneficiaries and victims of any new design. The results of such an analysis may underline the need for further debate and reflection. This appreciation of the consequences of intervention may also help to identify potential areas of conflict and to acknowledge accommodations that have been made by those involved. In Stowell and Champion (2000) and Champion and Stowell (1999a,b,c), we suggested modelling methods that can help in the exposition of ideas during IS design. The models produced during such an inquiry process will reflect the intended relationships to be maintained between individuals and their environment within any proposed intervention. Such models can then be used to support debate amongst participants and reflection by those concerned in order to facilitate these individuals in making a 
judgement on whether they perceive the character of an inquiry to be authentic or not.

\section{Learning}

Participants in the learning will have benefited individually from gaining an appreciation of the perspective of others. The active process of engaging in discussion may engender an awareness of the possibilities and constraints within a situation. Any agreed intervention (or non-intervention) in the situation would reflect the transformation that has occurred due to the process of inquiry and, thus, is a crucial element to reflect upon when considering authenticity. In undertaking an inquiry for IS development supported by systems ideas (see Stowell and West, 1994; Liang et al., 1998; Guo et al., 1999; Stowell, 2000; Stowell and Champion 2000), various models are constructed in order to support debate amongst participants. Those involved may or may not choose to implement the ideas that evolve through the debate supported by such models but, in either case, the debate will have moved the learning process forward and so these models can be considered to be direct outcomes of the learning. Learning is undertaken in an iterative cycle and is ideally neverending. There will be immediate learning and also knowledge that accumulates after action has been taken and reflection has occurred. The practical outcome of the inquiry will also include the success or failure of any intervention. Reflecting upon the learning outcomes will facilitate later evaluation of the intended and unintended consequences of action (or non-action) within the situation of concern. This process of ongoing reflection is part of the iterative learning cycle and enhances the shared appreciation of the participants, which in turn supports those implicated in making long-term judgements concerning authenticity.

\section{Summary}

These issues can be summarized using the mnemonic PEArL. It is our suggestion that the elements of the inquiry process highlighted by the PEArL mnemonic are crucial in demonstrating the authenticity of the knowledge created. The manner in which these issues are addressed reflects the character of the inquiry. It is fundamental to our approach that there is no attempt to offer an ethical judgement concerning decisions made in this regard. The intention is to use the themes emphasized in PEArL in order to facilitate an appreciation of the conduct of the inquiry. The elements described by PEArL are reflected upon and, if desired, recorded with the purpose of supporting those interested in making a judgement on whether they perceive the inquiry to be authentic or not. By raising questions in conversational natural English using the PEArL mnemonic as a guide, a practitioner would be supported in facilitating concerned individuals in gaining an appreciation of the authenticity of an inquiry. (Such a method of questioning is described in Stowell (2000), where the CATWOE mnemonic is applied in the use of the appreciative inquiry method (AIM) (West, 1995).)

The aim of the research undertaken within the UMISD (1998) project was to develop modelling methods for enabling those involved in a situation to be full partners in the design of their own IS. This is fundamentally different from current approaches, which are fixated by the impetus to provide a technical solution even if transitory in nature. Technology-driven design methods consistently fail to consider the issues and problems facing people in their attempts to take purposeful action in their situations. The ideas comprising PEArL have arisen from the work undertaken within the UMISD (1998) project and the UMISD team are currently taking advantage of a new, large-scale initiative involving the Open University and De Montfort University as an opportunity for undertaking field research into the PEArL mnemonic. The underpinning philosophy of our approach to IS design is to give primacy to the views of those involved in the situation in focus. Inquiry into a situation in order to create a shared appreciation of the diversity of views within a situation is paramount. Any learning achieved through inquiry needs to be demonstrated as being relevant to the issues at hand and also as having been derived in an authentic manner. Any proposed intervention or change is then more likely to be understood within the context of the whole situation and, thus, accepted by those concerned.

\section{Acknowledgement}

The authors wish to acknowledge the funding received from the UK Engineering and Physical Sciences Council (EPSRC) through research grant GR/M/02583

\section{References}

Avison, D.E. and Wood-Harper, A.T. (1990) Multiview: An Exploration in Information System Development (Blackwell Scientific Publications, Oxford).

Baskerville, R.L. and Wood-Harper, A.T. (1996) A critical perspective on action research as a method for information systems research. Journal of Information Technology, 11, 235-46.

Beyer, H. and Holtzblatt, K. (1997) Contextual Design: Defining Customer-centred Systems (Morgan Kaufmann, San Francisco).

Boudreau, M. (1997) Report on Panel Discussion 'Assessing Critical Social Theory Research in Information Systems' (Information Federation for Information Processing, Philadelphia). 
Burrell, G. and Morgan, G. (1979) Sociological Paradigms and Organisational Analysis (Heinemann Educational, London).

Champion, D. and Stowell, F.A. (1999a) Investigating interpretivist approaches to modelling client's requirements for information systems. In Proceedings of Systems Modelling for Business Process Improvement, University of Ulster, Coleraine, 29-31 March, pp. 83-93.

Champion, D. and Stowell, F.A. (1999b) An investigation into a prototype interpretivist approach to modelling requirements for information systems. In BIT 99, Manchester Metropolitan University, Manchester.

Champion, D. and Stowell, F.A. (1999c) Interpretive methods of inquiry for information systems analysis. In Seventh Interdisciplinary Information Management Talks (IDIMT99), Zadov, Czech Republic, 2-3 September, pp. 259-69.

Checkland, P.B. (1981) Systems Thinking Systems Practice (John Wiley, Chichester).

Checkland, P.B. (1983) O.R. and the systems movement: mappings and conflicts. Journal of Operational Research, 34(8), 661-75.

Checkland, P.B. and Holwell, S. (1998a) Information, Systems and Information Systems: Making Sense of the Field (John Wiley \& Sons, Chichester).

Checkland, P.B. and Holwell, S. (1998b) Action research: its nature and validity. Systemic Practice and Action Research, 11(1), 9-21.

Checkland, P.B. and Scholes, J. (1990) Soft Systems Methodology in Action (John Wiley, Chichester).

Checkland, P.B. and Scholes, J. (1999) Soft Systems Methodology in Action with a Thirty Years Retrospective on SSM (John Wiley, Chichester).

Clarke, S. and Lehaney, B. (1999) Organisational intervention and the problems of coercion. Systemist, 21, 40-52.

Dash, D.P. (1999) Current debates in action research.

Systemic Practice and Action Research, 12(5), 457-92. Doyle, K. and Wood, R.J. (1991) Systems thinking, systems practice, dangerous liaisons. Systemist, 13(1), 28-30.

D'Souza, D.F. and Wills, A.C. (1998) Objects, Components and Frameworks with UML: The Catalysis Approach (Addison Wesley, Harlow).

Farbey, B., Land, F. and Targett, D. (1993) How to Assess Your IT Investment: A Study of Methods and Practice (Butterworth Heinnemann, Oxford).

Finlay, P.N. and Wilson, J.N. (1997) Validity of decision support systems: towards a validation methodology. Systems Research and Behavioral Science, 14(3), 169-82.

Flood, R.L. and Jackson, M.C. (1991) Creative Problem Solving: Total Systems Intervention (John Wiley, London).

Foucault, M. (1980) In Power/Knowledge: Selected Interviews and Other Writings 1972-1977, Gordon, C. (ed.) (Harvester Press, Brighton).

Graham, I. (1998) Requirements Engineering and Rapid Development (Addison Wesley, London).

Guo, M., Wu, Z. and Stowell, F.A. (1999) Information systems specification within the framework of client-led design. In Proceedings of Systems Modelling for Business Process Improvement, University of Ulster, Coleraine, 29-31 March, pp. 94-106.

Habermas, J. (1990) Moral Consciousness and Communicative Action (translated by $\mathrm{C}$. Lenhardt and $\mathrm{S}$. Weber Nicholson) (Polity Press, Cambridge).
Heidegger, M. (1962) Being and Time (translated by J. Macquarrie and E. Robinson) (Harper \& Row, New York).

Jackson, M.A. (1983) System Development (Prentice-Hall, Chichester).

Kensing, F. and Blomberg, J. (1998) Participatory design: issues and concerns. Computer Supported Cooperative Work, 7, 167-85.

Kensing, F. and Munk-Madesen, A. (1993) Participatory design: structure in the tool box. Communications of ACM, 36(4), 78-85.

Korn, J. (1999) Qualitative modelling of information systems. In Synergy Matters: Proceedings of the Sixth International Conference of the UKSS, Castell, A.M., Gregory, A.J., Hindle, G.A., James, M.E. and Ragsdell, G. (eds) (Plenum, New York), pp. 571-6.

Lewis, P. (1993) Linking soft systems methodology with datafocused information systems development. Information Systems Journal, 3(3), 169-86.

Liang, Y., West, D. and Stowell, F.A. (1998) An interpretivist approach to IS definition using object modelling. Information Systems Journal, 8, 163-80.

Lycett, M. and Paul, R.J. (1999) Information systems development: a perspective on the challenge of evolutionary complexity. European Journal of Information Systems, 8, 127-35.

Midgley, G. (1997) Dealing with coercion: critical systems heuristics and beyond. Systems Practice, 10(1), 37-57.

Mingers, J. (1995) Using soft systems methodology in the design of information systems. In Information Systems Provision: The Contribution of Soft Systems Methodology, Stowell, F.A. (ed.) (McGraw-Hill, London), pp. 18-50.

Mumford, E. (1996) Systems Design: Ethical Tools for Ethical Change (Macmillan, London).

Mumford, E. (1997) The reality of participative systems design: contributing to stability in a rocking boat. Information Systems Journal, 7, 309-22.

Mumford, E. and Weir, M. (1979) Computer Systems in Work Design - The ETHICS Method (Associated Business Press, London).

Myers, M.D. (1994) Dialectical hermeneutics: a theoretical framework for the implementation of information systems. Information Systems Journal, 5, 51-70.

Nierstrasz, O. and Meijler, T.D. (1995) Research directions in software composition. ACM Computing Surveys, 27(2), 159-80.

Pooley, R. and Stevens, P. (1999) Using UML: Software Engineering with Objects and Components (Addison-Wesley, Harlow).

Powell, P. (1992) Information technology evaluation: is it different? Journal of the Operational Research Society, 43(1), $29-42$.

Pressman, R.S. (1997) Software Engineering: A Practitioner's Approach (McGraw-Hill, London).

Sartre, J.P. (1966) Being and Nothingness (Washington Square Press, New York).

Savage, A. and Mingers, J. (1996) A framework for linking soft systems methodology (SSM) and Jackson system development (JSD). Information Systems Journal, 6, 109-29.

Sawyer, K. (1992) A contribution towards the debate on linking SSM to IS. Systemist, 14(3), 199-201. 
SEBPC (1996) Systems Engineering for Business Process

Change.

Smith, S.A. (1997) Modelling the discharge decision-making process in the domain of mental health care. In Proceed- ings of the Fifth International Conference of the UKSS Systems for Sustainability, People, Organisations and Environments, Stowell, F.A., Ison, R.L., Armson, R. Holloway, J. Jackson, S. and McRobb, S. (eds), pp. 625-30.

Smithson, S. and Hirschheim, R. (1998) Analysing infor-mation systems evaluation: another look at an old problem. European Journal of Information Systems, 7, 158-74.

Smyth, D.S. and Checkland, P.B. (1976) Using a systems approach: the structure of root definitions. Journal of Applied Systems Analysis, 5(1), 75-83.

Somekh, B. (1995) The contribution of action research to development in social endeavours: a position paper on action research methodology. British Educational Research Journal, 21(3), 339-55.

Sommerville, I. and Sawyer, P. (1997) Requirements Engineering: A Good Practice Guide (John Wiley \& Sons, Chichester).

Stowell, F.A. (1985) Experiences with SSM and data analysis. Information Technology Training, 48-50.

Stowell, F.A. (1989) Change, organisation, power and the metaphor: commodity. PhD dissertation, University of Lancaster.

Stowell, F.A. (1991) Towards client-led development of information systems. Information Systems Journal, 1, 173-89.

Stowell, F.A. (2000) Modelling IS requirements for complex systems. In Systems Modelling for Business Process Improvement, Bustard, D.W., Kawalek, P. and Norris, M.T. (eds) (Artech House), pp. 171-86.

Stowell, F.A. and Champion, D. (2000) Interpretivist modelling for information system definition. In Systems Engineering for Business Process Change, Henderson, P. (ed.) (Springer), pp. 106-16.

Stowell, F.A. and West, D. (1994) Client-led Design: A Systemic Approach to Information System Definition (McGraw-Hill, London).

Stowell, F.A., West, D. and Stansfield, M. (1997) Action research as a framework for IS research. In Information Systems: An Emerging Discipline?, Mingers, J. and Stowell, F.A. (eds) (McGraw Hill, London).

Susman, G.I. and Evered, R.D. (1978) An assessment of the scientific merits of action research. Administrative Science Quarterly, 23, 582-602.

Sykes, J.B. (ed.) (1996) Oxford English Dictionary, 6th edn (Clarendon Press, Oxford).

Tsoukas, H. (1993) Analogical reasoning and knowledge generation in organization theory. Organization Studies, 14(3), 323-46.

Ulrich, W. (1983) Critical Heuristics of Social Planning: A New Approach to Practical Philosophy (Haupt, Berne).

Ulrich, W. (1991) Critical heuristics of social systems design. In Critical Systems Thinking: Directed Readings, Flood, R.L. and Jackson, M.C. (eds) (Wiley, Chichester), pp.

103-15. 
UMISD (1998) Unified Mechanism for Information Systems Definition.

Vickers, G. (1965) The Art of Judgement. A Study in Policy Making (Chapman \& Hall, London).

Vickers, G. (1970) Freedom in a Rocking Boat (Allen Lane, London).

Walsham, G. (1995) Interpretive case studies in IS research: nature and method. European Journal of Information Systems, 4, 74-81.

West, D. (1995) The appreciative inquiry method: a systemic approach to information systems requirements analysis. In Information System Provision: The Contribution of Soft Systems Methodology, Stowell, F.A. (ed.) (London, McGraw-Hill), pp. 140-58.

Wilson, B. (1984) Systems: Concepts, Methodologies, and Applications (Wiley, Chichester).

\section{Biographical notes:}

Donna Champion is a research student at De Montfort University, Milton Keynes, UK. Her main research interests include using systems thinking to support the exploration of problem situations, in particular during information system design and development. She is a member of the Interpretivist Modelling Group and is currently working on a project funded by the EPSRC Engineering for Business Process Change (SEBPC) programme. Donna's recent publications include, A Unified Mechanism for Information System Definition in Action, and A Report on an Action Research Field Study.

Frank Stowell is currently Director of the Milton Keynes campus of De Montfort University. His research has focused on methods of information sys- tems development and the impact of IT on organiza- tions. He is a long-serving member of the executive committee of the United Kingdom Systems Society; was President of the United Kingdom Academy for Information Systemsfor two years and is now Vice- president. He edits the journal Systemist and has writ- ten extensively on information systems. He has been published in various Information Systems journals, books and international conferences. He is joint fund holder on the EPSRC project "A Unified Mechanism for Information Systems Research" and was a member of the HEFQC Benchmarking Committee for Computing.

Address for correspondence: D. Champion, Department of Computer and Information Sciences, De Montfort University, Milton Keynes, UK. 